\title{
Performance Improvement of VCRS Using Waste Heat Recovery Method
}

\author{
M.Mahesh $^{1}$, P.Thangavel ${ }^{2}$, B.Arulpriyan ${ }^{3}$, M.S Abdullah ${ }^{4}$, P.Gokul $^{5}$ \\ ${ }^{1}$ Assistant Professor, Kongu Engineering College, India, mahesh25391@gmail.com \\ ${ }^{2}$ Assistant Professor, Kongu Engineering College, India, ptvel@kongu.ac.in \\ ${ }^{3}$ B.E. Student, Kongu Engineering College, India, arulb1998@gmail.com \\ ${ }^{4}$ B.E. Student, Kongu Engineering College, India, abdullahms218@gmail.com \\ ${ }^{5}$ B.E. Student, Kongu Engineering College, India, gokul17299@gmail.com
}

\begin{abstract}
The principle goal of this undertaken project is to enhance the coefficient of performance (COP) of a Refrigerator using waste heat recovery method. The issue right now is insufficient cooling of the condenser reduces the COP. The way to decrease abundance heat and the presentation examination is done by utilizing R134a and Hydrocarbon mixtures (R290 50\% and R600a 50\%) refrigerants. The technique utilized right now water cooled condenser arrangement is given and cooled utilizing water which is splashed in fog structure condenser. The water gets warmed by the waste warmth removed from the water cooled condenser and furthermore it decreases the condenser outlet temperature which builds the COP value. The final results obtained using the setup shows the COP value of refrigerator was increased in the condenser cooled by water than the condenser cooled by air.
\end{abstract}

Key words : COP, Load Performance, Performance analysis, Water Cooled Condenser.

\section{INTRODUCTION}

\subsection{Refrigeration process}

The main function of the Refrigeration system is to produce cooling effect. Four main thermodynamic processes are involved in the VCRS system for cooling are namely Compression, Condensation, Expansion and Evaporation. The medium used in this process is known as refrigerant. Refrigerants are used to absorb and extract the heat from the cooling room, and then reject the heat. The refrigerant is filled in the compressor where the compression processes occurs and there will be a high pressure and high temperature during this process. After this condensation process occurs where the refrigerant is cooled to reduce the temperature and there will be a high pressure and low temperature. After condensation process, Expansion process occurs there will be a low pressure and low temperature. After expansion process, evaporation process occurs there the heat transformation occurs and there will be a low pressure and high temperature. The refrigerant is reused in thermodynamic process. Here modification is done in the condensation process by using the water cooled condenser for reducing the refrigerant temperature.

\subsection{Literature Review}

K. Srithar et.al (2018) presented a paper on Energy recovery from a vapour compression refrigeration system using humidification dehumidification desalination. The purpose of this research is to increase the efficiency (COP) of a vapor compression cooling device by Recovery of waste heat from condenser and evaporator using dehumidification desalination process. [2] Such improvements increased the refrigeration system's COP by up to 7.6 with a distillate water output of $0.41 / \mathrm{m} 2 \mathrm{~h}$. [15] The COP of the modified refrigerator configuration reaches up to 7.6 with the inclusion of turbulator in dehumidifier and covering the condenser with gunny bag which is 2.09 times higher than the conventional refrigerator with the addition of purified water output extracted from the condenser and evaporator low heat source [1].

Lakshya Soni et.al (2016) presented a paper on Waste heat recovery system from domestic refrigerator for water and air heating. In this paper, Attempts have been made to use waste heat from refrigerator condenser. [4] Superheat is a part of waste heat which is recovered by using a heat recovery unit for useful purposes. The difference in temperature obtained between inlet and outlet of water exceeds $10^{\circ} \mathrm{C}$. [10] The amount of heat transferred by the condenser cooled by water is sufficient to increase the latter's temperature at the end of five hours, at $60^{\circ} \mathrm{C}$. [12] The use of heat recovery system shows the enhancement of maximum setup up to 2 in COP and also the reduction of power consumption [3]. 
Thangavel et.al (2013) presented a paper on Simulation Analysis of Compression Refrigeration Cycle with different Refrigerants. In this paper refrigerants used are R134a, R12 and R600a and R290 mixture; R290 and R600a refrigerants are combined in separate mass fractions roughly $20 \%+80 \%$, $25 \%+75 \%, 50 \%+50 \%$ and $75 \%+25 \%$. [9] The synthesis of R290 and R600a at a 50 per cent concentration each of the hydrocarbon refrigerants group has optimum efficiency in terms of higher refrigeration effect and COP that is used in the domestic refrigerator [5].

S. Wongwise .al (2005) presented a paper on Experimental study of hydrocarbon mixtures to replace HFC-134a in a domestic refrigerator. [11] This research introduces an HFC-134a substitute in a domestic fridge. In this study propane (R290), butane (R600), and isobutane (R600a) were investigated. [8] The energy used the compressor power and the temperature and pressure of the refrigerant at the compressor inlet and outlet are reported and analyzed, as well as the temperature distributions at different locations in the refrigerator. [6] The refrigerant mixtures used are divided into three groups: the three-hydrocarbon mixture, the two-hydrocarbon mix and the two-hydrocarbon and HFC-134a mixture. [14] The experiments are performed with the refrigerants at an ambient temperature of $25^{\circ} \mathrm{C}$ under the same no charge condition. [13] The findings show that propane/butane 60 percent $/ 40$ percent is the most suitable alternative refrigerant to HFC-134a. The refrigerator filled with 100 percent propane displays the lowest energy consumption per day [7].

\subsection{Literature Summary}

- ODP and GWP are the two main factors for the depletion of ozone layer. CFC and HFC gases have high ODP and GWP values.

- Hydrocarbon refrigerants are adequate compounds and affordable in nature and are very attractive to use in domestic refrigerator.

- The COP of the refrigerator can be increased by waste heat recovery method.

- Using alternative refrigerants for R134a will reduce the global warming temperature.

- Volumetric cooling, for the range of operating conditions considered for R134a and $\mathrm{HC}$ blend are same.

- Hydrocarbon refrigerants provide favorable environmental conditions, i.e. zero potential for ozone loss and nearly zero potential for global warming.

- There are many ways to recover the heat from the condenser of a refrigerator. By condenser cooled by water or by condenser cooled by air. The COP of the refrigerator will also increase by heat recovery system and efficiency of the system also improves.

\section{EXPERIMENTAL SYSTEM}

\subsection{Fabrication of condenser cooled by water}

Figure 1 shows the condenser cooled by water is attached to the refrigerator rear side. The refrigeration system incorporates both the condenser cooled by air and the condenser cooled by water. The condenser cooled by water inlet is attached to the compressor outlet using the T-joints and the condenser gate valve for connecting both. The condenser cooled by water outlet is attached to the extending valve. The condenser cooled by water is made of a copper tube, and the aluminum coating is made on the condenser to avoid corrosion. The gate valves are used for the supply of compressed refrigerant from one of the condensers in both condenser inlets and outlets.

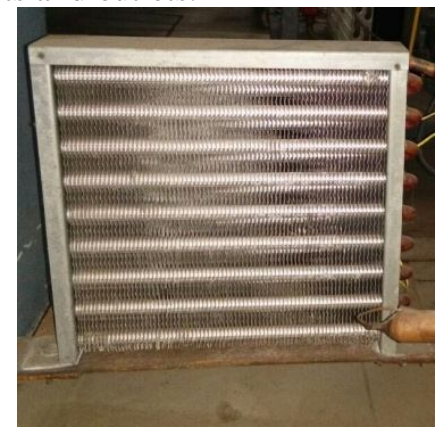

Figure 1: Water cooled condenser

\subsection{Experimental setup}

Figure 2 shows the experimental setup of the refrigerator connected with both the condenser cooled by air and the condenser cooled by water. The duct is placed over the condenser cooled by water to spray the water in mist form from one end of the duct. The mist form water is sprayed using the paint sprayer gun. The water which is sprayed on the condenser will absorb the heat from the condenser and the condenser gets cooled, so the outlet temperature of the condenser decreases and it increases the cooling effect in the VCRS. The water gets dropped from the condenser are collected using the tray and the water gets heated using the heat absorbed from the condenser.

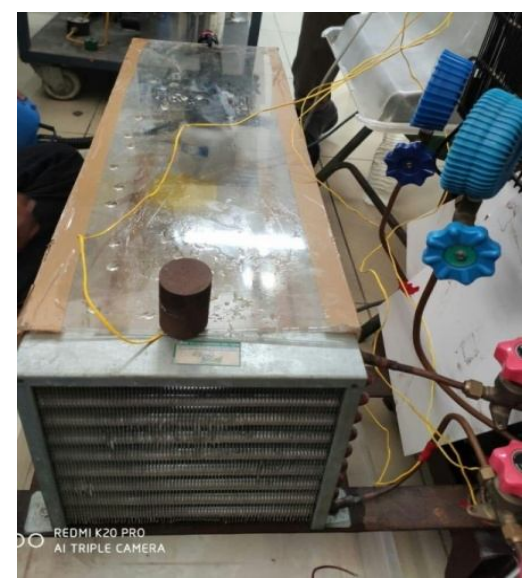

Figure 2: Experimental Setup 


\section{ANALYSIS OF THE CYCLE}

Performance of vapour compression refrigeration system (VCRS) is calculated with the condenser cooled by air and the condenser cooled by water. Various loads like no load and 6 litres were used for observations. The various observations like refrigeration effect, condenser heat rejection rate, compressor work and COP are considered for both the condenser cooled by air and the condenser cooled by water to find the improvement in performance of VCRS.

$\mathrm{P}_{1}$ - Suction pressure (bar)

$\mathrm{P}_{2}$ - Delivery pressure (bar)

$\mathrm{T} 1$ - Refrigerant temperature at compressor inlet $\left({ }^{\circ} \mathrm{C}\right)$

$\mathrm{T} 2$ - Refrigerant temperature at compressor outlet $\left({ }^{\circ} \mathrm{C}\right)$

T3 - Refrigerant temperature at condenser outlet $\left({ }^{\circ} \mathrm{C}\right)$

$\mathrm{T}_{4}$ - Refrigerant temperature at expansion outlet $\left({ }^{\circ} \mathrm{C}\right)$

Enthalpy at inlet of compressor

$\mathrm{h} 1=\mathrm{hg}+\mathrm{Cpv}\left(\mathrm{T}_{\text {sup }}-\mathrm{T}_{\text {sat }}\right)$

Enthalpy at outlet of compressor

$\mathrm{h} 2=\mathrm{hg}+\mathrm{C}_{\mathrm{pv}}\left(\mathrm{T}_{\text {sup }}-\mathrm{T}_{\text {sat }}\right)$

Enthalpy at condenser outlet

h3 = hf-Cpl(Tsat-T3)

Enthalpy at evaporator inlet

$\mathrm{h} 3=\mathrm{h} 4$

\section{RESULT AND DISCUSSIONS}

\subsection{Performance improvement analysis of VCRS in R134a under no load}

VCRS is operated under no load with condenser cooled by air and the condenser cooled by water. So the condensation effect, refrigeration effect, compressor work and COP of the VCRS have been obtained and comparisons are given below.

\subsubsection{Comparison of COP}

Figure 3 shows the COP of VCRS with condenser cooled by air and the condenser cooled by water. COP obtained in the VCRS with air cooled condenser is 4.51 and with water cooled condenser is 5.00 for no load condition. It is observed that the COP of VCRS with water cooled condenser is increased about $10.86 \%$ than the COP with air cooled condenser process.

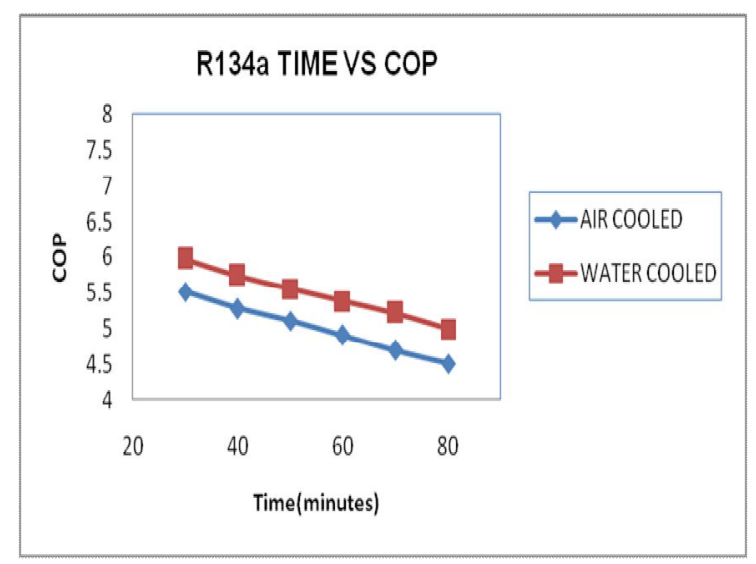

Figure 3: COP Comparison

\subsubsection{Comparison of refrigeration effect}

Figure 4 shows the refrigeration effect (RE) of VCRS with condenser cooled by air and the condenser cooled by water. RE obtained in the VCRS with air cooled condenser is 165.24 $\mathrm{kJ} / \mathrm{kg}$ and with water cooled condenser is $171.7 \mathrm{~kJ} / \mathrm{kg}$ for no load condition. It is observed that the RE of VCRS with water cooled condenser is increased about $3.91 \%$ than the RE with air cooled condenser process.

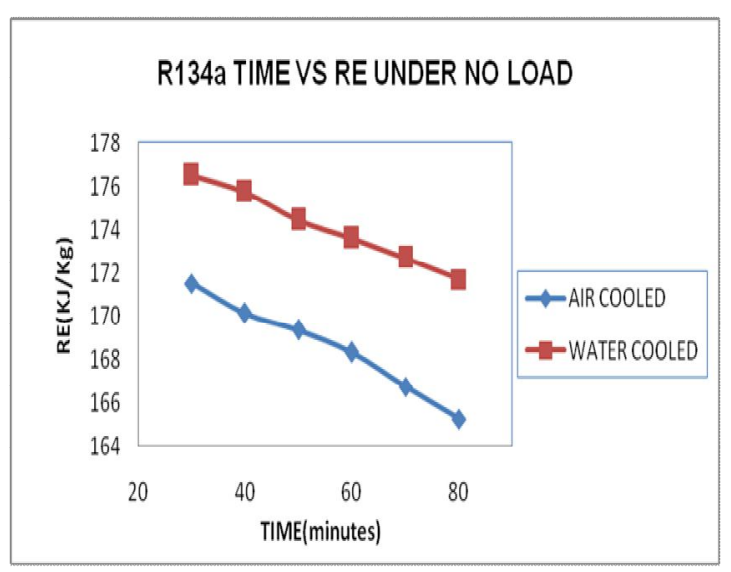

Figure 4: RE Comparison

\subsection{Performance improvement analysis of VCRS in R134A under 6 litres load}

VCRS is operated under 6litres load with condenser cooled by air and the condenser cooled by water. So the condensation effect, refrigeration effect, compressor work and COP of the VCRS have been obtained and comparisons are given below.

\subsubsection{Comparison of COP}

Figure 5 shows the COP of VCRS with condenser cooled by air and the condenser cooled by water. COP obtained in the VCRS with air cooled condenser is 6.86 and with water cooled condenser is 7.78 for 6litres load condition. It is observed that the COP of VCRS with water cooled condenser is increased about $13.4 \%$ than the COP with air cooled condenser process.

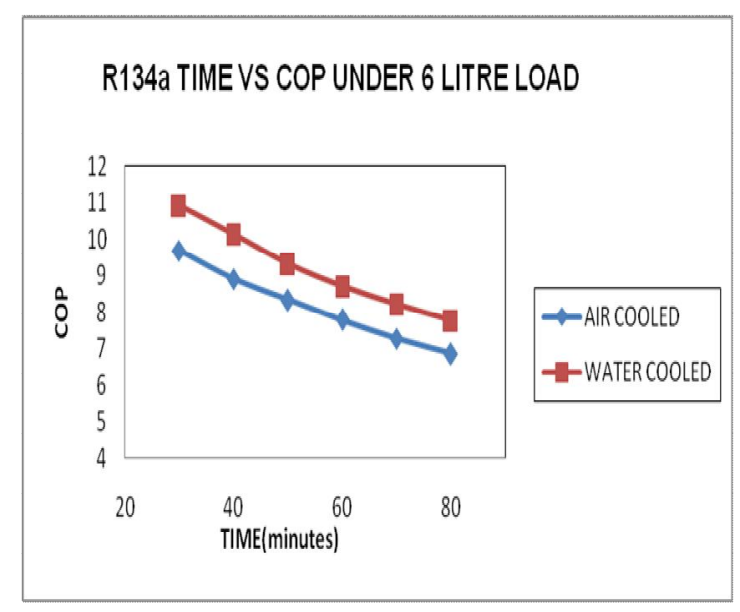

Figure 5: COP Comparison 
M.Mahesh et al., International Journal of Emerging Trends in Engineering Research, 8(5), May 2020, 1964 - 1971

\subsubsection{Comparison of refrigeration effect}

Figure 6 shows the refrigeration effect (RE) of VCRS with condenser cooled by air and the condenser cooled by water. RE obtained in the VCRS with air cooled condenser is 165.74 $\mathrm{kJ} / \mathrm{kg}$ and with water cooled condenser is $177.94 \mathrm{~kJ} / \mathrm{kg}$ for 6litres load condition. It is observed that the RE of VCRS with water cooled condenser is increased about $7.3 \%$ than the RE with air cooled condenser process.

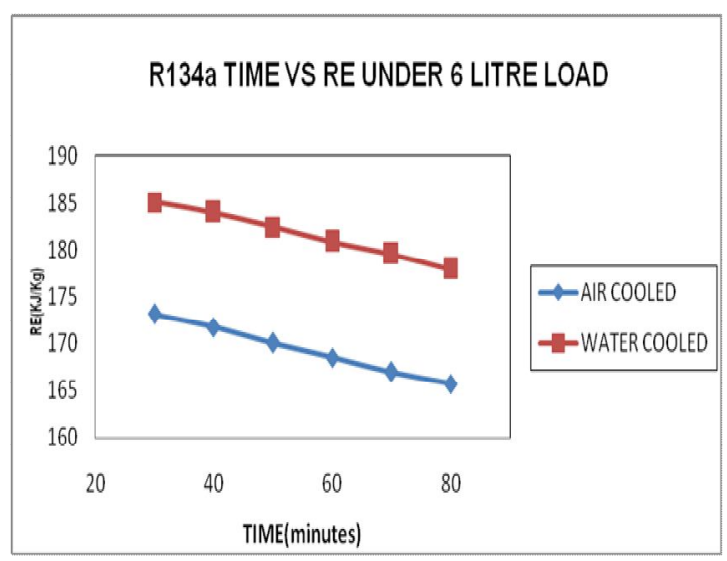

Figure 6: RE Comparison

\subsection{Performance improvement analysis of VCRS in mixtures of R290(50\%) and R600a(50\%) under no load}

VCRS is operated under no load with condenser cooled by air and the condenser cooled by water. So the condensation effect, refrigeration effect, compressor work and COP of the VCRS have been obtained and comparisons are given below.

\subsubsection{Comparison of COP}

Figure 7 shows the COP of VCRS with condenser cooled by air and the condenser cooled by water. COP obtained in the VCRS with air cooled condenser is 4.22 and with water cooled condenser is 4.64 for no load condition. It is observed that the COP of VCRS with water cooled condenser is increased about 9.9\% than the COP with air cooled condenser.

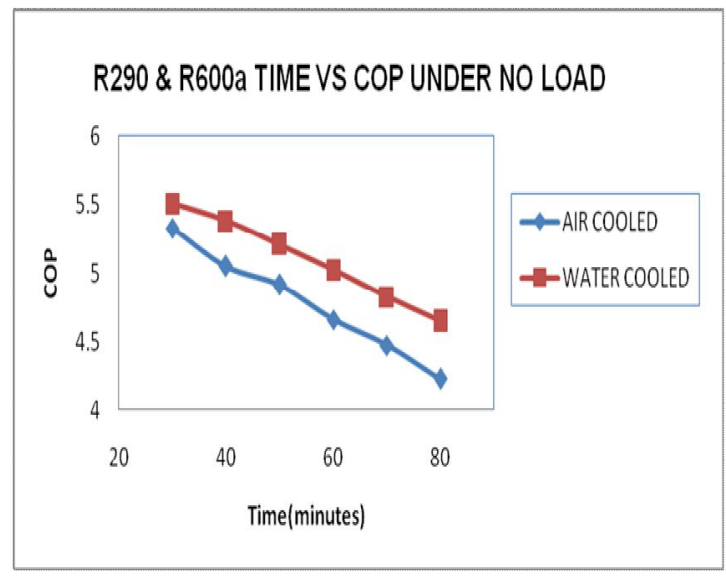

Figure 7: COP Comparison

\subsubsection{Comparison of refrigeration effect}

Figure 8 shows the refrigeration effect (RE) of VCRS with condenser cooled by air and the condenser cooled by water. RE obtained in the VCRS with air cooled condenser is 312.41 $\mathrm{kJ} / \mathrm{kg}$ and with water cooled condenser is $325.78 \mathrm{~kJ} / \mathrm{kg}$ for no load condition. It is observed that the RE of VCRS with water cooled condenser is increased about $4.2 \%$ than the RE with air cooled condenser process.

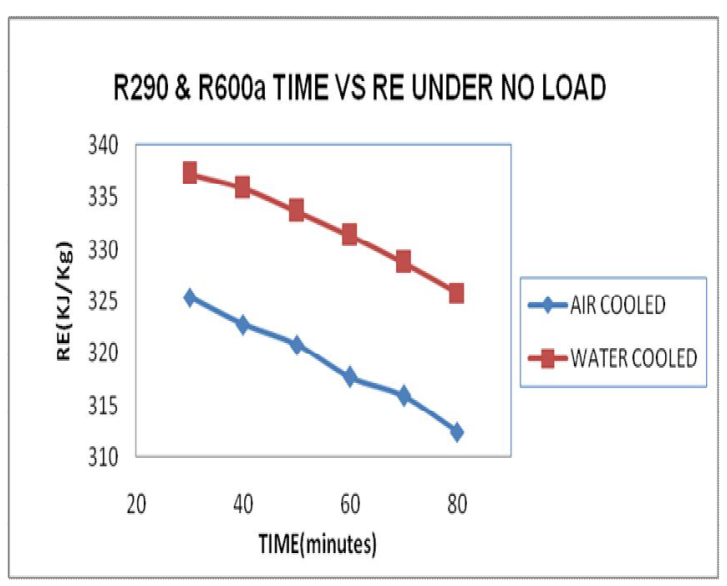

Figure 8: RE Comparison

\subsection{Performance improvement analysis of VCRS in mixtures of $\mathrm{R} 290(50 \%)$ and $\mathrm{R} 600 \mathrm{a}(50 \%)$ under 6 litres} load

VCRS is operated under 6litres load with condenser cooled by air and the condenser cooled by water. So the condensation effect, refrigeration effect, compressor work and COP of the VCRS have been obtained and comparisons are given below.

\subsubsection{Comparison of COP}

Figure 9 shows the COP of VCRS with condenser cooled by air and the condenser cooled by water. COP obtained in the VCRS with air cooled condenser is 6.18 and with water cooled condenser is 7.02 for 6litres load condition. It is observed that the COP of VCRS with water cooled condenser is increased about $13.5 \%$ than the COP with air cooled condenser process.

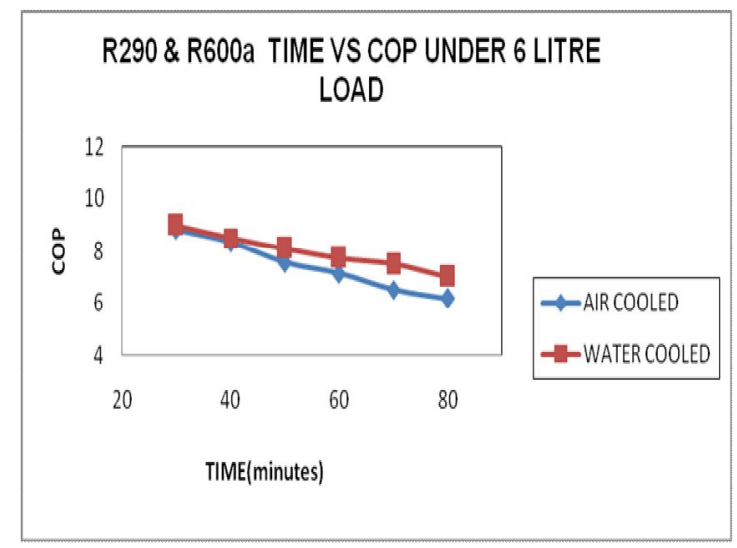

Figure 9: COP Comparison 


\subsubsection{Comparison of refrigeration effect}

Figure 10 shows the refrigeration effect (RE) of VCRS with condenser cooled by air and the condenser cooled by water. RE obtained in the VCRS with air cooled condenser is 331.38 $\mathrm{kJ} / \mathrm{kg}$ and with water cooled condenser is $346.31 \mathrm{~kJ} / \mathrm{kg}$ for 6litres load condition. It is observed that the RE of VCRS with water cooled condenser is increased about $4.5 \%$ than the RE with air cooled condenser process.

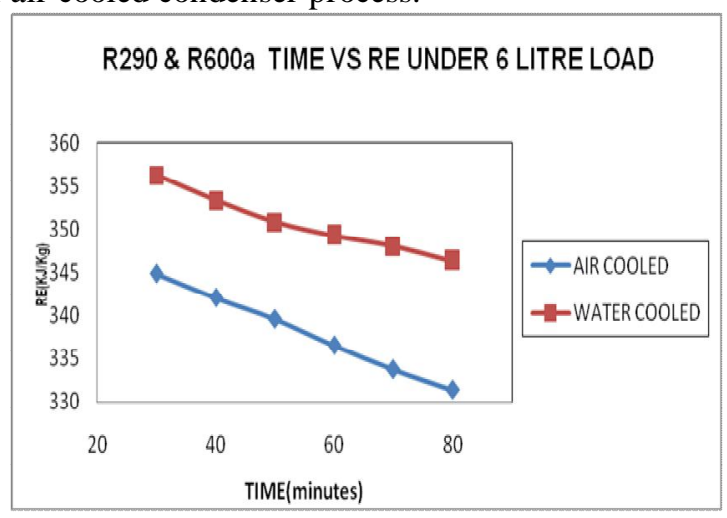

Figure 10: RE Comparison

4.5 Performance improvement analysis of VCRS with air cooled condenser of refrigerants r134a and hydrocarbon mixtures of $\mathbf{R} 290(50 \%)$ and R600a (50\%) under 6 litre load

VCRS is operated under 6litre load with air cooled condenser. So the condensation effect, refrigeration effect, compressor work and COP of the VCRS have been obtained and comparisons are given below.

\subsubsection{Comparison of COP}

Figure 11 shows the comparison of COP of VCRS with air cooled condenser for refrigerants R134a and Hydrocarbon mixtures. COP obtained in R134a is 6.86 and Hydrocarbon mixture is 6.18 for 6litre load condition. It is observed that the COP of VCRS with R134a is increased by $9.91 \%$ than the COP of Hydrocarbon mixtures.

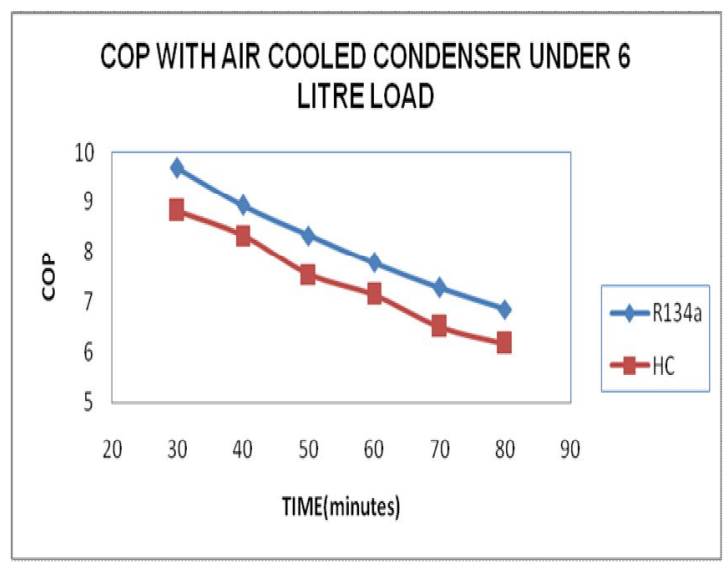

Figure 11: Comparison of COP with air cooled condenser of R134a and Hydrocarbon mixtures

\subsubsection{Comparison of Refrigeration effect}

Figure 12 shows comparison of refrigeration effect of VCRS with air cooled condenser for refrigerants R134a and Hydrocarbon mixtures. Refrigeration effect obtained in $\mathrm{R} 134 \mathrm{a}$ is $165.74 \mathrm{~kJ} / \mathrm{kg}$ and Hydrocarbon mixture is 331.38 $\mathrm{kJ} / \mathrm{kg}$ for 6litre load condition. It is observed that the refrigeration effect of VCRS with R134a is decreased by about 99.93\% than the refrigeration effect of Hydrocarbon mixtures.

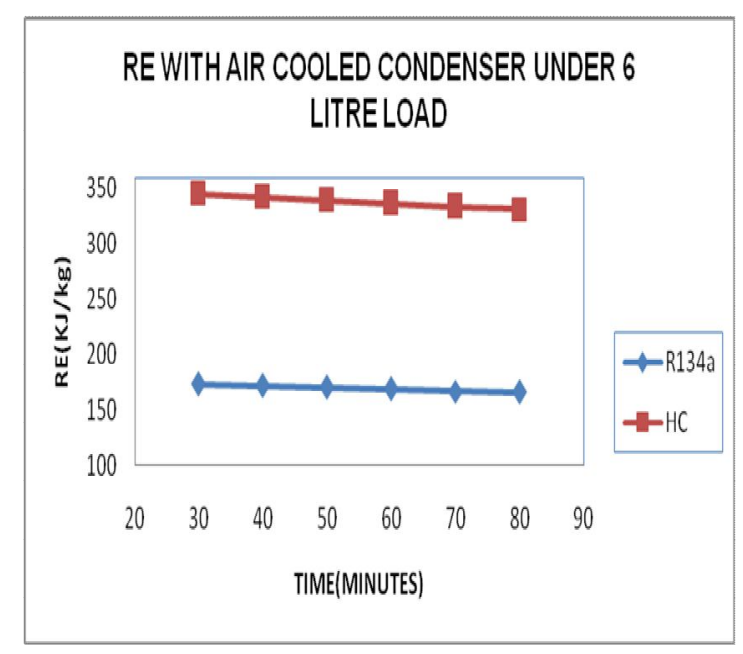

Figure 12: Comparison of Refrigeration effect with air cooled condenser of R134a and Hydrocarbon mixtures

\subsubsection{Comparison of condenser effect}

Figure 13 shows comparison of condenser effect of VCRS with air cooled condenser for refrigerants R134a and Hydrocarbon mixtures. Condenser effect obtained in R134a is $189.87 \mathrm{~kJ} / \mathrm{kg}$ and Hydrocarbon mixture is $384.99 \mathrm{~kJ} / \mathrm{kg}$ for 6litre load condition. It is observed that the condenser effect of VCRS with R134a is decreased by about $102.76 \%$ than the condenser effect of Hydrocarbon mixtures.

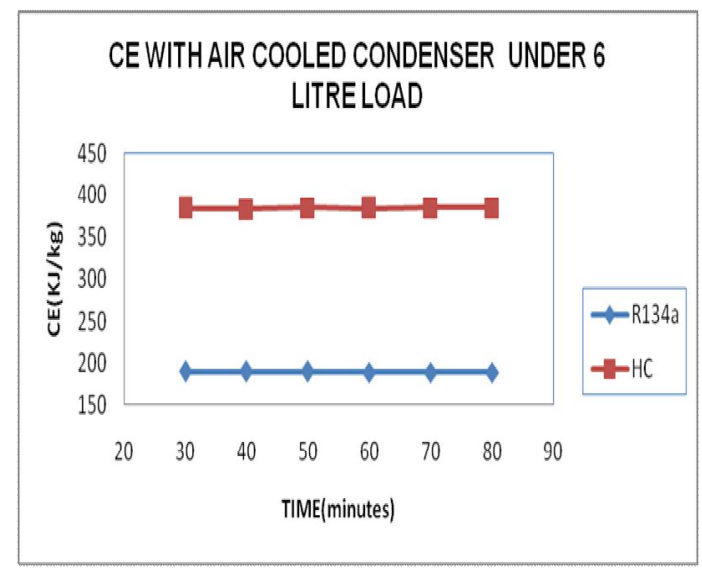

Figure 13: Comparison of condenser effect with air cooled condenser of R134a and Hydrocarbon mixtures 
M.Mahesh et al., International Journal of Emerging Trends in Engineering Research, 8(5), May 2020, 1964 - 1971

\subsubsection{Comparison of Compressor work}

Figure 14 shows comparison of compressor work of VCRS with air cooled condenser for refrigerants R134a and Hydrocarbon mixtures. Compressor work obtained in R134a is $24.13 \mathrm{~kJ} / \mathrm{kg}$ and Hydrocarbon mixture is $53.60 \mathrm{~kJ} / \mathrm{kg}$ for 6litre load condition. It is observed that the compressor work of VCRS with R134a is decreased by about $122.13 \%$ than the compressor work of Hydrocarbon mixtures.

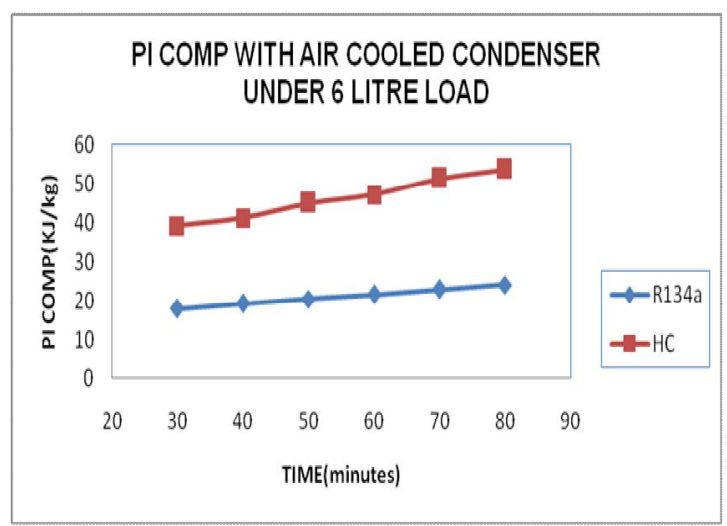

Figure 14: Comparison of compressor work with air cooled condenser of R134a and Hydrocarbon mixtures

4.6 Performance improvement analysis of VCRS with water cooled condenser of refrigerants r134a and hydrocarbon mixtures of R290 (50\%) and R600a (50\%) under 6 litre load

VCRS is operated under 6litre load with water cooled condenser. So the condensation effect, refrigeration effect, compressor work and COP of the VCRS have been obtained and comparisons are given below.

\subsubsection{Comparison of COP}

Figure 15 shows the comparison of COP of VCRS with water cooled condenser for refrigerants R134a and Hydrocarbon mixtures. COP obtained in R134a is 7.78 and Hydrocarbon mixture is 7.02 for 6litre load condition. It is observed that the COP of VCRS with R134a is increased by $9.76 \%$ than the COP of Hydrocarbon mixtures.

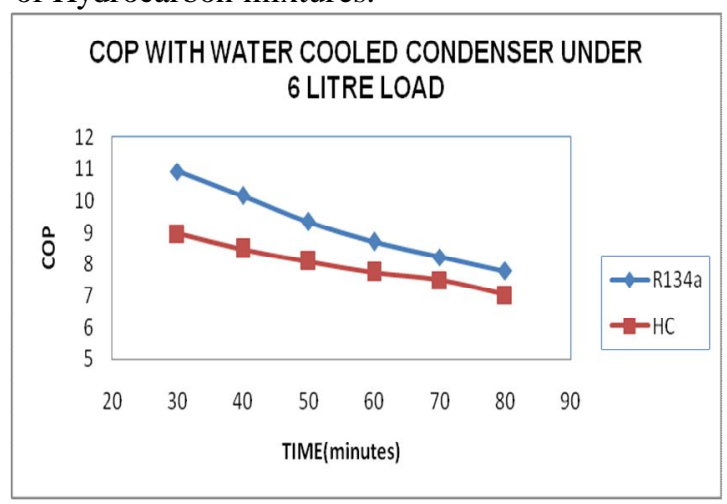

Figure 15: Comparison of COP with water cooled condenser of R134a and Hydrocarbon mixtures

\subsubsection{Comparison of Refrigeration effect}

Figure 16 shows comparison of refrigeration effect of VCRS with water cooled condenser for refrigerants R134a and Hydrocarbon mixtures. Refrigeration effect obtained in $\mathrm{R} 134 \mathrm{a}$ is $177.94 \mathrm{~kJ} / \mathrm{kg}$ and Hydrocarbon mixture is 346.31 $\mathrm{kJ} / \mathrm{kg}$ for 6litre load condition. It is observed that the refrigeration effect of VCRS with R134a is decreased by about 94.62\% than the refrigeration effect of Hydrocarbon mixtures.

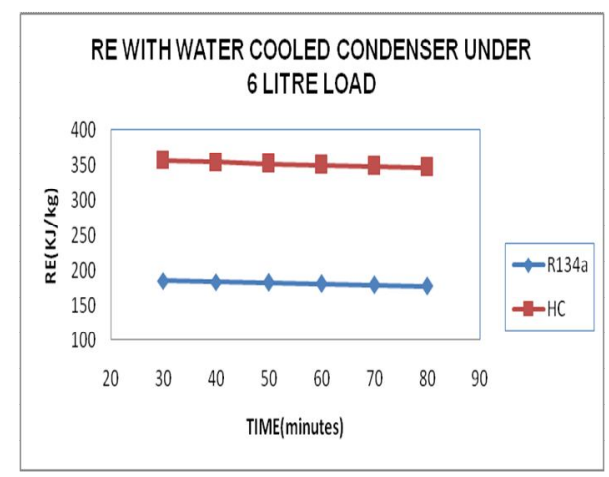

Figure 16: Comparison of Refrigeration effect with water cooled condenser of R134a and Hydrocarbon mixtures

\subsubsection{Comparison of condenser effect}

Figure 17 shows comparison of condenser effect of VCRS with water cooled condenser for refrigerants R134a and Hydrocarbon mixtures. Condenser effect obtained in R134a is $200.81 \mathrm{~kJ} / \mathrm{kg}$ and Hydrocarbon mixture is $395.60 \mathrm{~kJ} / \mathrm{kg}$ for 6litre load condition. It is observed that the condenser effect of VCRS with R134a is decreased by about $97 \%$ than the condenser effect of Hydrocarbon mixtures.

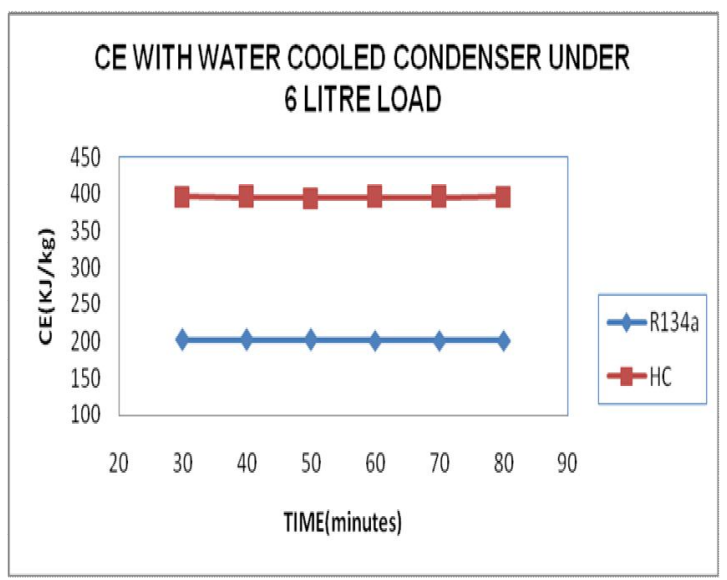

Figure 17: Comparison of condenser effect with water cooled condenser of R134a and Hydrocarbon mixtures

\subsubsection{Comparison of compressor work}

Figure 18 shows comparison of compressor work of VCRS with water cooled condenser for refrigerants R134a and Hydrocarbon mixtures. Compressor work obtained in R134a is $22.87 \mathrm{~kJ} / \mathrm{kg}$ and Hydrocarbon mixture is $49.29 \mathrm{~kJ} / \mathrm{kg}$ for 
M.Mahesh et al., International Journal of Emerging Trends in Engineering Research, 8(5), May 2020, 1964 - 1971

6litre load condition. It is observed that the compressor work of VCRS with R134a is decreased by about $115.52 \%$ than the compressor work of Hydrocarbon mixtures.

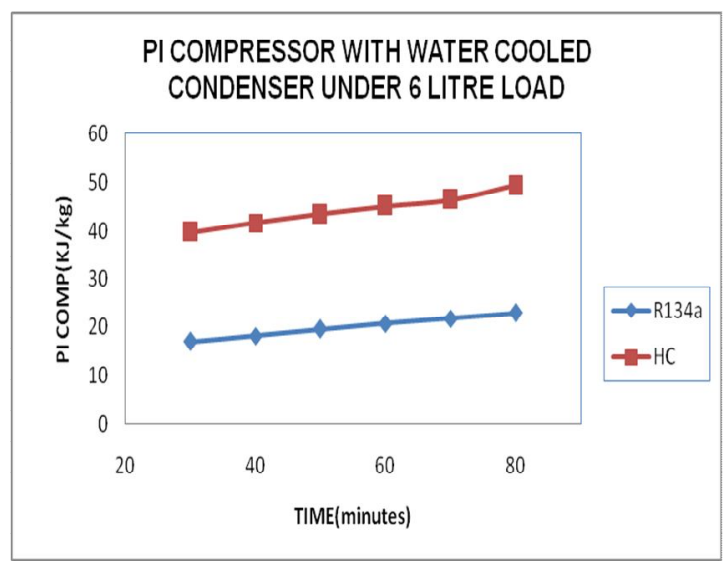

Figure 18: Comparison of compressor work with water cooled condenser of R134a and Hydrocarbon mixtures

\section{CONCLUSION}

The refrigeration effect, condenser work, and refrigerator COP are enhanced with condenser cooled by water as compared to condenser cooled by air in the refrigerator. Compressor work performance has decreased in refrigerator with water cooled condenser. By considering the various loads in the evaporator, the improvements are given for maximum load (6 litres),

- Refrigeration effect for refrigerant R134a and mixtures of $\mathrm{R} 290(50 \%)$ and $\mathrm{R} 600 \mathrm{a}(50 \%)$ is increased by $7.3 \%$ and $4.5 \%$ respectively by using water cooled condenser.

- Condenser effect for refrigerant R134a and mixtures of $\mathrm{R} 290(50 \%)$ and $\mathrm{R} 600 \mathrm{a}(50 \%)$ is increased by $5.7 \%$ and $2.7 \%$ respectively by using water cooled condenser.

- Compressor work for refrigerant R134a and mixtures of $\mathrm{R} 290(50 \%)$ and R600a(50\%) is decreased by $5.2 \%$ and $8.0 \%$ respectively by using water cooled condenser.

- COP for refrigerant R134a and mixtures of R290(50\%) and $\mathrm{R} 600 \mathrm{a}(50 \%)$ is increased by $13.4 \%$ and $13.5 \%$ respectively by using water cooled condenser.

- Replacing R134a by hydrocarbon mixture (R290 and R600a) the COP of VCRS with condenser cooled by air and the condenser cooled by water has decreased about $9.91 \%$ and $9.76 \%$.

- Replacing R134a by hydrocarbon mixture (R290 and R600a) the refrigeration effect of VCRS with condenser cooled by air and the condenser cooled by water has increased about $99.93 \%$ and $94.62 \%$.

- Replacing R134a by hydrocarbon mixture (R290 and R600a) the condenser effect of VCRS with condenser cooled by air and the condenser cooled by water has increased about $102.76 \%$ and $97 \%$.

- Replacing R134a by hydrocarbon mixture (R290 and R600a) the Power input to compressor using condenser cooled by air and the condenser cooled by water has increased about $122.13 \%$ and $115.52 \%$.

- The Global Warming Potential (GWP) of refrigerant $\mathrm{R} 134 \mathrm{a}$ is 1600 and the mixtures of R290(50\%) and $\mathrm{R} 600 \mathrm{a}(50 \%)$ is 20 ,So the mixtures of $\mathrm{R} 290(50 \%)$ and $\mathrm{R} 600 \mathrm{a}(50 \%)$ is recommended. mixtures of $\mathrm{R} 290(50 \%)$ and $\mathrm{R} 600 \mathrm{a}(50 \%)$ is recommended.

From the above conclusions, refrigerator efficiency can be enhanced by using water-cooled condenser as opposed to the standard domestic refrigerator with air-cooled condenser.

\section{REFERENCES}

1. R. Santosh, G. Kumaresan, S. Selvaraj, T. Arunkumar, R. Velraj, Investigation of humidification dehumidification desalination system through waste heat recovery from household air conditioning unit, Desalination, Vol.467, pp.1-11, 2019. https://doi.org/10.1016/j.desal.2019.05.016

2. K. Srithar, T. Rajaseenivasan, M. Arulmani, R. Gnanavel, M. Vivar, Manuel Fuentes, Energy recovery from a vapour compression refrigeration system using humidification dehumidification desalination, Desalination, Vol.439:pp.155-161, 2018. https://doi.org/10.1016/j.desal.2018.04.008

3. Y.S. Lee, C.C. Su, Experimental studies of isobutane (R600a) as the refrigerant in domestic refrigeration system, Applied Thermal Engineering, Vol.22, pp.507-519, 2002.

https://doi.org/10.1016/S1359-4311(01)00106-5

4. Lakshya Soni, Pawan Kumar, Rahul Goyal, Waste heat recovery system from domestic refrigerator for water and air heating, International Journal of Engineering Sciences \& Research Technology, Vol.5,pp.700-705, 2016.

5. Soma A. Biswas, Sandeep M. Joshi, Waste heat recovery from domestic refrigerator, International Journal of Current Engineering and Scientific Research, Vol.4, pp.12-17, 2017.

6. S. Wongwises, N. Chimres, Experimental study of hydrocarbon mixtures to replace HFC-134a in a domestic refrigerator, Energy Conversion and Management, Vol.46,pp. 85-100, 2005.

https://doi.org/10.1016/j.enconman.2004.02.011

7. A. M. Vibhute, Avinash M. Patil, Waste heat recovery in Domestic Refrigerator, International Engineering Research Journal, Vol.27, pp131-133, 2015.

8. Angelo Maiorino, Ciro Aprea, Manuel Ges`u Del Duca, Rodrigo Llopis, Daniel S'anchez, Ramºn Cabello, $R-152 a$ as an alternative refrigerant to $R-134 a$ in domestic refrigerators, International Journal of Refrigeration,Vol.96,pp.106-116, 2018.

https://doi.org/10.1016/j.ijrefrig.2018.09.020

9. P.Thangavel, Dr.P.Somasundaram, T.Sivakumar, C.Selva Kumar, G.Vetriselvan, Simulation Analysis of Compression Refrigeration Cycle with Different 
M.Mahesh et al., International Journal of Emerging Trends in Engineering Research, 8(5), May 2020, 1964 - 1971

Refrigerants, International Journal of Engineering and Innovative Technology,Vol.2,pp.127-131, 2013.

10. AE Kharat, Dr. DM Mate, SD Kathwate, Experimental study of alternative refrigerants to replace R134a in a domestic refrigerator, International Journal of Academic Research and Development,Vol.3,pp.111-120, 2018.

11. Adrian Mota-Babiloni, Joaquin Navarro-Esbri, Angel Barragan-Cervera, Francisco Moles, Bernardo Peris, Experimental study of an R1234ze(E)/R134a mixture (R450A) as R134a replacement, International Journal of Refrigeration, Vol.51,pp.52-58, 2015. https://doi.org/10.1016/j.ijrefrig.2014.12.010

12. M. Mohanraj, S. Jayaraj, C. Muraleedharan, Comparative assessment of environment-friendly alternatives to $\mathbf{R} 134 a$ in domestic refrigerators, Energy efficiency,Vol.1,pp.189-198, 2008. https://doi.org/10.1007/s12053-008-9012-z

13. R. S. Powade, A. A.Rane, A. D. Rane, O. S. Sutar, V. S. Bagade, Performance Investigation of Refrigerants R290 and R134a as an Alternative to R22, International Journal for Research in Applied Science \& Engineering Technology,Vol.6,pp.4668-4676, 2018. https://doi.org/10.22214/ijraset.2018.4767

14. Eko Julianto, Waluyo adi siswanto,Marwan Effandy, Characteristics of Temperature changes and Stress of Float Glass under Heat Radiation, International Journal of Emerging Trends in Engineering Research, vol. 7 no:9, page 228-233,2019.

https://doi.org/10.30534/ijeter/2019/03792019

15. Sergey Mikhailovich Usikov, Simulation of Heat Transfer by Water Heating Convectors, International Journal of Emerging Trends in Engineering Research, vol. 8 no 3,page 726-734,2020.

https://doi.org/10.30534/ijeter/2020/19832020 